\title{
An Empirical Study of Turnover Intentions in Call Centre Industry of Pakistan
}

\author{
Muhammad Aamir Shafique Khan, Jianguo Du \\ School of Management, Jiangsu University, Zhenjiang, China \\ Email: aamir lionheart@hotmail.com
}

Received 21 September 2014; revised 24 October 2014; accepted 23 November 2014

Academic Editor: Luca Solari, University of Milan, Italy

Copyright (C) 2014 by authors and Scientific Research Publishing Inc.

This work is licensed under the Creative Commons Attribution International License (CC BY). http://creativecommons.org/licenses/by/4.0/

cc) (i) Open Access

\begin{abstract}
All over the world organizations have realized that skilled labor and talented employees develop the organization for better incentives and for improvements. How to reduce employee's turnover intention is a very critical challenge for today's HR managers and supervisors. Pay better incentives, high salaries and employee's motivational techniques have been useless and old practices of the human resource management. This study is conducted to understand the factors that directly affect the turnover intentions in call center industry of Pakistan. Sample size of 137 call centre agents from call centre industry of Pakistan were used to examine relationship between turnover intentions, workload, compensation and benefits and job conditions as well. Various factors manipulate turnover intentions, including: workload and type of work, salary and other benefits, Organizational climate and culture, supervision and interpersonal relationships, position, sovereignty, job conditions, entirely environment in the call centers, the nature of tasks to be performed and job outcomes.
\end{abstract}

\section{Keywords}

Turnover Intention, Compensation, Organizational Climate, Workload, Compensation and Benefits, Job Conditions

\section{Introduction}

Turnover intentions has drawn an unparalleled attention of researchers over last few years as many of today's organizations are facing this issue more than any other era.

It has a wide scope because it becomes a worldwide problem and every manager and supervisor wants to know that why employees leaves the organizations. Though there are many factors but one of the possible fac- 
tors that may forecast labour turnover is the employee's perception of his capability to do the job [1].

By overcoming this problem organizations can retain their skilled and talented employees and decreased their cost as well. Providing education and training seems key and spending time creating the "right" environment in which staff feels empowered to report potential risk events is paramount [2]. No one can deny the importance of call centers; call centers have become the first contact centers with employees in almost every type of organizations. And serve the customers in sense that organizations wants to create a long term relationship with customers and build and satisfaction and retain them for long term as well. Call centers ever more seen as a service that customers expected from any organization. Call centers today employ over 800,000 people and occupy upwards of 65 million square feet of commercial property [3].

The major importance of this study is to analyze the factors that effecting turnover in this sector.

The topic which is chosen that is the turnovers intentions in call center industry of Pakistan, because this very serious issue in this sector that why employees leave call center jobs what are the reasons behind the huge turnover in this industry. It is a big opportunity to explore that what are those variable that affects the turnover intentions. Turnover in call centers is a big problem that faces managers today. Psychologists note that many young individuals employed in call centers are vulnerable to burn-out stress syndrome (BOSS), symptoms of which include constant exhaustion, sleeplessness and variation of the body's 24-hour biological pulse [4]. It affects the cost and quality of the services. Turnover differs by the area or city. An exclusive characteristic of call centers is that they observe the holiday schedules of their customers rather than the holidays of their own country [5]. In more specialized or metropolitan areas employment opportunities are high then the less developed and rural areas. In developed areas turnover is low than the less developed areas. Average turnover rate in call center industry is $30 \%$ to $45 \%$ [6]. Turnover is a too much headache for all the managers because it decreases the costs and marketability of the call centers and increases the cost of training and recruitment and selection of the employees. There are some other costs that face call centers in cause of turnover such as the cost of advertising and maintaining of human resource team, the cost of interviewing and assessments and the cost of training which includes the cost of trainer's wages and the place or conference which is hired for training. There are many causes of turnover in call centers such as non competitive compensation, high stress, unpleasant physical and interpersonal working conditions, monotony, poor direct supervision, limited chances of career advancement and workload etc. The work environment of low turnover call centers is distinct as a low stress and burnout, supportive supervision, varied work activities, team orientation and flexible rules and regulations. Call center jobs also produce high levels of psychological pressure for employees, which can upshot health mutilation and demotivation [7]. It is shown that some countries have a severe shortage of employees and face the mobility of the employees from one place to another. Over the past 40 years mangers and researchers are researching this severe issue that why employees leave the organization. For managers it is big problem because turnover of the employees increase too much expenses of the employees.

One of the problems with turnover in call centers is that employees are hired but they can't retain themselves with the entire environment. They attend orientations and spend few weeks in getting training after getting training they reject the job and thinks that it is not suitable for them. According to a recent survey 1000 companies hiring the wrong call center representatives often 26 times the average salary. Most of the call centers employees spent their time on attending the phone calls, most centers requires that their employees should respond 40 to 100 calls daily. With passing the every day the job becomes boring so the managers and supervisors should change the workplace environment and job conditions with the passage of time so the employees are not getting bored. Career path is also a major part that increased the turnover because the employees can't see their career and they thinks that they spent their life in this place. Call centers should have a set of precautionary tests and indicators so that managers can be aware of the onset of depersonalization and arousing exhaustion and take counteractive steps [8]. Understanding call centre stressors and their impact on burnout is a necessary and critical starting point in developing and implementing programs designed to address the dysfunctional effects of stressors and their differential impact on inbound and outbound call center agents [9].

Call center is a computer operated centralized office that deals with call and services to deal with the customers. Computer based telecommunications systems escort to efficient time management of customer issues, firms are becoming highly dependent on call centers to address customers' concerns ranging from billing issues to accounts; problems with products or services [10]. It deals with a huge variety of customers in all industry sectors. It offers a variety of services from very simple to complex. Role of call centers are to improve company's performance and decrease the extra costs due to unnecessary work done. Call centers purpose to provide effi- 
cient services to customers on phone calls. In call centers call are handled by a group of skilled of call center agents who provide the optimum services to the customers and solve their problems as well. The activities of call centers are to customer acquisition and retention of old customers. Though call centers are valuable resources for managing customer relationships, these have also gained the reputation of "electronic panopticons" and "dark santanic mills" [11]. Society plays an important role in determining the worth of jobs for employees; this determines the perception of call centers as good or bad workplaces [12]. A call center survey is a best method to increase the effectiveness of call center professionals, maximize customer satisfaction and minimize the churn of customers. There are three types of call centers such as:

- Internal call centers: are designed to deal with the technical and human resource problems.

- Inbound call centers: are provide services such as technical support, product and service and information.

- Outbound call centers: are providing services on sales and services related telemarketing.

\section{Theoretical Model}

Figure 1 is showing the theoretical model of the study and is depicting the clear picture that the workload on the employees, compensation and benefits given to them and the job conditions are the factors which ignites the turnover intentions and motivates the employees either to stay in or leave the organization.

\section{Research Methodology}

\subsection{Research Design}

Quantitative approach is used for this study. For this study turnover intention is chosen as a dependent variable. Workload, compensation and benefits and job conditions are elected as independent variables.

\subsection{Data Collection Tools}

Data of all variables is collected through questionnaires. The questionnaires filled by the sample of employees of inbound and outbound call centers. All the respondents filled the questionnaires. Likert type scale used to check the strongly agree, agree, neutral, disagree and strongly disagree and depends on the condition of the questions.

Essentially, questionnaire is the set of printed or written questions with a choice of answers, devised for the purposes of a survey or statistical study.

\subsection{Sampling Techniques and Sample}

\subsubsection{Population}

The population of this study is all the agents of call centre industry which are currently operating in Pakistan whether it is inbound, internal and outbound and providing their services to all the customers of all over the world directly and indirectly. nQuery software was used to find out the sample size.

\subsubsection{Sample Size}

The data collected from the sample size of 137 participants from inbound, internal and outbound call centers as well. 50 questionnaires filled from the Ufone, 50 from Warid and other remaining from the interlink communications which operate its business as an outbound call centre in the Pakistan.

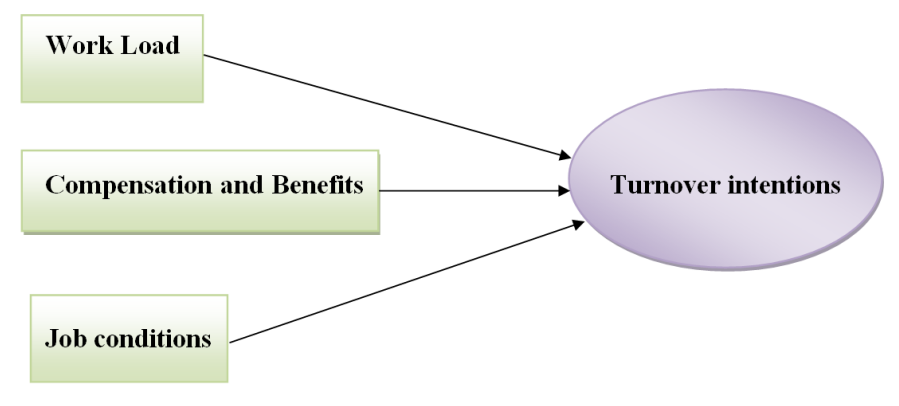

Figure 1. Research model. 


\subsection{Measures}

For measuring turnover intentions in call centers work load, compensation and benefits and job conditions used as variables. Data from participants collected through filling questionnaires from them. The answers in questionnaire contain 5 points as $5=$ Strongly Agree, $4=$ Agree, $3=$ Neutral, $2=$ Disagree, $1=$ Strongly Disagree. The survey contained total of 28 questions which took approximately 8 - 10 minutes to complete.

\subsubsection{Turnover Intentions}

The questionnaire for measuring turnover intentions is adapted from VIGODA 2000. In the questionnaire there are 5 items include to measure the turnover intentions. The scale is categorized in 5 point likert scale that ranged from 1 = Strongly Disagree to 5 = strongly agree. The reliability analysis exposed that value of cronbach's Alpha is 0.753 that is reliable.

\subsubsection{Compensation and Benefits}

There are six items include measuring the compensation and benefits. 5 point likert scale is also used to measure this variable. The reliability analysis exposed that value of cronbach's Alpha is 0.727 that is also reliable.

\subsubsection{Job Conditions}

There are 6 items to measure the reliability of job conditions. 5 point likert scale is also used to measure job conditions. The reliability analysis showing that value of cronbach's Alpha is 0.705 that is also reliable.

\subsubsection{Workload}

Also Employee's actions toward the workload are measured. All the items in this questionnaire in order to measure turnover intentions have been adapted from authors Allan Toomings. The reliability analysis showing that value of Cronbach's Alpha is 0.804 that is also reliable according to scale.

\subsection{Questionnaire's Authors}

The questionnaires are adapted from different authors as their study related. The questionnaires are adapted from previous researches [13] [14].

\subsection{Methodology}

For evaluation purpose SPSS software is used. The data is evaluated into two parts first part of data will base on descriptive statistics the can be defined as "Descriptive statistics comprises the kind of analysis which is used to describe the population, and when the population that is small enough to permit to include every case" second part of data will lead towards Inferential Statistics that can be defined as "You are trying to reach conclusions that extend beyond the immediate data alone. For this inferential statistics is used to make judgments of the probability that an observed difference between groups is a dependable one or one that might have happened by chance in this study"

To analyze the data tests used are (descriptive summary, reliability, correlation and regression) descriptive summary tells the mean and standard deviation value of the variable. Correlation describes significance value which shows there is relationship or not or it also shows that relationship is positive or negative and regression tells the value of coefficient, value of $\mathrm{R}$ square and the value of $\mathrm{F}$.

\section{Results}

\subsection{Demographics}

The demographic variables like gender, age and educational qualification are presented in Table 1.

\subsubsection{Gender}

The first variable which is shown in this questionnaire is gender which was analyzed with two close ended choices. Males were coded as 0 and females were coded as 1 . The result from the table reveals that out of total 137 respondents 105 are males and remaining 32 are females are targeted. In ratio $76.6 \%$ are males and other remaining $23.4 \%$ are females. There is also a column of valid percentage to adjust the missing respondents. 
Table 1. Demographic variables.

\begin{tabular}{ccccc}
\hline Demographic & Variables & Frequency & Percent & Valid percent \\
\hline \multirow{2}{*}{ Gender } & Male & 105 & 76.6 & 76.6 \\
& Female & 32 & 23.4 & 23.4 \\
& $16-25$ & 83 & 60.6 & 60.6 \\
Age & $26-35$ & 49 & 35.8 & 35.8 \\
& $36-45$ & 4 & 2.9 & 2.9 \\
& $46-55$ & 1 & 0.7 & 0.7 \\
Educational qualification & Matriculation & 1 & 0.7 & 0.7 \\
& Intermediate & 14 & 10.2 & 10.4 \\
& Graduation & 71 & 51.8 & 52.6 \\
\hline
\end{tabular}

\subsubsection{Age}

Age is the second variable in demographic part which is used to determine the employee's ages are belonging to which groups. The ages of participants was analyzed by dividing into four categories such as, $16-25,26-35$, 36 - 45 and 46 - 55. Result from the frequency table shows that maximum number of employees belonging into first group that is 16 - 25 years old. Out of total 137 employees, 83 are belonging to this group. That is the $60.6 \%$ of the total sample size. 49 employees are belonging to the range of $26-35$ that contains the $35.8 \%$ of total sample size. According to the table in $3^{\text {rd }}$ category, which falls in 36 - 45 having only 4 employees, which are the $2.9 \%$ of the total population. Only 1 employee belongs to the last category which is $46-55$, that is only 0.7 of the total respondents.

\subsubsection{Education}

The third and last most important category of the demographic profile is education. The basic objective of this category is to know the education level of employees. In order to know the level of education of employees the questions is divided into 5 categories, such as matriculation, intermediate, graduate, masters and post graduate. The frequency table shows that only 1 employee belongs to first category that is matriculation which is the $0.7 \%$ of total participants.

14 employees belong to second category that is intermediate which is the $10.2 \%$ of the total respondents. There are 71 employees fall in $3^{\text {rd }}$ category that is graduation which is the $51.8 \%$ employees of total sample size. There are more employees in this category rather than others. Out of 137, the education level of 48 employees is masters that are the $35.0 \%$ of total sample size. According to this table only 1 employees fall in last category that is the post graduate, which is $0.7 \%$ only.

\subsection{Correlations}

Table 2 is showing the correlation analysis. Correlation analysis is used to check the relationship between variable whether these are strong or weak. If the value of correlation coefficient is more than 0.7 it means there is a high correlation between two variables.

If the value ranges between 0.4 to 0.7 it means that there is a moderate correlation between the two variables.

If the value of correlation coefficient is below than 0.4 it means there exists a very weak or no relation. Results for hypothesis, "there exist significant relationship between workload and turnover intentions" shows that there significant and positive relationship between the two variables at correlation coefficient $r=0.320$ and significance level of 0.000 . So the first hypothesis is accepted.

Result for hypothesis, "there exist a significant relationship between compensation and benefits and turnover intentions shows that the hypothesis has been rejected as correlation coefficient $r=-0.167$ which is negative and insignificant. 
Table 2. Correlation analysis.

\begin{tabular}{|c|c|c|c|c|c|}
\hline & & $\begin{array}{l}\text { Turnover } \\
\text { intentions }\end{array}$ & $\begin{array}{l}\text { Compensation } \\
\text { and benefits }\end{array}$ & Job conditions & Workload \\
\hline \multirow{3}{*}{$\begin{array}{l}\text { Turnover } \\
\text { intentions }\end{array}$} & Pearson correlation & 1 & & & \\
\hline & Sig. (2-tailed) & & & & \\
\hline & $\mathrm{N}$ & 137 & & & \\
\hline \multirow{3}{*}{$\begin{array}{l}\text { Compensation } \\
\text { and benefits }\end{array}$} & Pearson correlation & -0.167 & 1 & & \\
\hline & Sig. (2-tailed) & 0.051 & & & \\
\hline & $\mathrm{N}$ & 137 & 137 & & \\
\hline \multirow{3}{*}{ Job conditions } & Pearson correlation & $-0.182^{*}$ & $0.376^{* *}$ & 1 & \\
\hline & Sig. (2-tailed) & 0.034 & 0.000 & & \\
\hline & $\mathrm{N}$ & 137 & 137 & 137 & \\
\hline \multirow{3}{*}{ Workload } & Pearson correlation & $0.320^{* * *}$ & 0.076 & $0.249^{* *}$ & 1 \\
\hline & Sig. (2-tailed) & 0.000 & 0.379 & 0.003 & \\
\hline & $\mathrm{N}$ & 137 & 137 & 137 & 137 \\
\hline
\end{tabular}

"Correlation is significant at the 0.05 level (2-tailed); ${ }^{* *}$ Correlation is significant at the 0.01 level (2-tailed).

Result for hypothesis, "there exist a significant relationship between job conditions and turnover intentions shows that the hypothesis has been rejected as the value is negative because the value of $r=-0.182$ which is insignificant as well.

\subsection{Regression}

Regression analysis was used to evaluate the impact of independent variable on dependent variable by using version of 17 of SPSS. The independent variable workload, compensation and benefits and job conditions were regressed with the dependent variable turnover intentions.

According to regression analysis in Table 3 the value of value $\mathrm{R}^{2}$ is 0.102 which shows that $10 \%$ variation in turnover intentions is explained by workload and remaining by other factors. Value of Beta $=0.320$ at significance level of 0.000 showed strong positive impact of workload on turnover intentions on the basis of Beta value and its significance so this hypothesis is accepted.

In second row the value of $\mathrm{R}^{2}$ is 0.28 which shows that $28 \%$ variation in turnover intentions is explained by compensation and benefits and remaining by other factors. The other factors are demographic variables. Value of Beta $=-0.167$ at significance level of 0.51 show weak negative, impact of compensation and benefits on turnover intentions on the basis of Beta value and it is insignificance so the hypothesis is rejected.

In third row the value of $\mathrm{R}^{2}$ is 0.033 which shows that $0.03 \%$ variation in turnover intentions is explained by job conditions and remaining by other factors. Value of Beta $=-0.182$ at significance level of 0.034 which shows that negative impact of job conditions on turnover intentions on the basis of Beta value it is insignificance this hypothesis is also rejected.

\section{Discussion}

After the study of turnover intentions in all internal and external call centers it is came to knowledge that all call centers are facing this severe problem and this becomes the global issue in all over the world. The future of Pakistan telecom including call centers is being considered seriously by the government, in order to free it from regulations [15]. Some employees are happy with their job and with their supervisors and organizations as well. Employee's contribution and participation is another way to make your own employees feel good about working with you as an employee [16]. But after the survey it was realized that many employees are unhappy with their job because of lack of compensation and benefits, too much work-load, and job conditions as well. Due to these factors effectiveness and efficiency of call center agents are reduced and it also increases the turnover intentions in all the organizations. Some telecommunication companies took this issue serious and invest on the retention of employees. Effectively retention of all the call centre agents can overall increase the productivity of 
Table 3. Regression analysis.

\begin{tabular}{cccc}
\hline Predictor variables & \multicolumn{3}{c}{ Turnover intentions } \\
\cline { 2 - 4 } & $\mathbf{B}$ & $\mathbf{R}^{2}$ & Significance \\
\hline Work load & 0.320 & 0.102 & 0.000 \\
Compensation \& benefits & -0.167 & 0.28 & 0.51 \\
Job conditions & -0.182 & 0.033 & 0.034 \\
\hline
\end{tabular}

organization and employees as well; ultimately the result will be in-crease the overall output of the organization.

As forecasted hypothesis 1 of this study got strong support from the result, and assist in accepting the first hypothesis that there exists significant and strong relationship between workload and turnover intentions. So the first hypothesis of this study is accepted. It means that heavy workloads can increase the turnover intentions in call center industry of Pakistan.

Hypothesis 2 of this study is rejected because there are negative and insignificance relationship between compensations and benefits and turnover intentions. So the results did not support the second hypothesis.

Hypothesis 3 of this study also rejected because there are negative and insignificance relationship between job conditions and turnover intentions. So the third and last hypothesis also did not support the study and it is rejected by this study as well.

\subsection{Limitations}

Though we tried to make all efforts to make this study very comprehensive and useful but still there exists some limitations like the number of respondents because despite the fact we tried to make sure and to convince them that it is purely an academic research work but they still were reluctant to respond to our questions. Also, there can be other variables which can be used based on the cultural factors. The most important factor is that the call centre industry is a newly flourishing industry in Pakistan and still needs to be investigated more with passing time.

\subsection{Recommendations for Further Study}

This research can be conducted on large scale in all over the Pakistan because call centers are located in all large cities of Pakistan. By increasing sample size the accuracy of result will be definitely increased. The further study can be conducted on this topic because this is related to turnover intentions researcher can know other factors that affect turnover intentions. Another area of study can be determine the most effective and efficient policies to retention of employees in all internal, inbound and outbound call centers. There are many other stressors that can be identified by maximizing the research area and sample size.

\subsection{Suggestions}

By the analysis of turnover intentions it is found that many flaws are in retention of employees. There needed some improvements in all type of call centers. There found different strong and weak relationships between dependent and independent variable which can enhance the research on this topic furthermore. It is compulsory for every organization to make sure that the retention strategies are proper implemented.

There are some suggestions for every type of organizations.

\subsubsection{Recruitment and Selection}

Recruitment and selection procedures in call centers should be transparent and on merit. Biasness should be removed. With the help of proper recruitment and selection procedure the hired candidates will be talented and skilled. It is compulsory for organizations to give equitable salary and other compensation and benefits according to their qualification, skills and experience as well. All the organizations should be focused on these points:

- Fair compensation structure.

- Communication of compensation structure.

- Benefits according to employee's caliber.

- Career ladder.

- Compensation on performance based. 


\subsubsection{Training and Development}

There should be giving a proper training to every level of employees according to their job. Training can add other skills and abilities in employee for performing the current job. And development can add values in personnel's for future coming challenges and jobs. Evaluation of training and development should be analyzed to check the results of training. Proper training and development can reduce the turnover and it can also save the time and money as well.

\subsubsection{Performance Appraisal}

In call centre industry employees leave organizations because they are not gets proper incentives and other benefits. There should be proper performance appraisal system should be implemented so that employees can evaluate on their task done not favoritism. There should be a proper reward whether these are monetary or non monetary given employees according to their level.

\subsubsection{Employee Relations}

The relationships among employees and supervisors should be strong so that they can share everything without any hesitations. Culture plays an important role in developing good relations between and employees and supervisors.

\section{References}

[1] Bryce, C., Cheevers, C. and Webb, R. (2013) Operational Risk Escalation: An Empirical Analysis of UK Call Centres. International Review of Financial Analysis, 30, 298-307. http://dx.doi.org/10.1016/j.irfa.2013.05.002

[2] Al-Refaei, Y.S.Y. and Omran, K.A.M. (1992) Organizational and Psychological Determinants of Employee Turnover in Kuwait. International Journal of Public Sector Management, 5.

[3] Snow, J. (2005) UK Call Centres: Crossroads of an Industry. Journal of Property Investment \& Finance, 23, 525-532. http://dx.doi.org/10.1108/14635780510626565

[4] Budhwar, P.S., Varma, A., Malhotra, N. and Mukherjee, A. (2009) Insights into the Indian Call Centre Industry: Can Internal Marketing Help Tackle High Employee Turnover? Journal of Services Marketing, 23, 351-362. http://dx.doi.org/10.1108/08876040910973459

[5] Hechanova, M.R.M. (2013) The Call Center as a Revolving Door: A Philippine Perspective. Personnel Review, 42, 349-365. http://dx.doi.org/10.1108/00483481311320444

[6] Reynolds, P. (2005) The Power of One. 3rd Edition, The Call Center School Press, Tennessee.

[7] Kraemer, T. and Gouthier, M.H.J. (2014) How Organizational Pride and Emotional Exhaustion Explain Turnover Intentions in Call Centers. Journal of Service Management, 25, 125-148. http://dx.doi.org/10.1108/JOSM-07-2013-0173

[8] Choi, S., Cheong, K.J. and Feinberg, R.A. (2012) Moderating Effects of Supervisor Support, Monetary Rewards, and Career Paths on the Relationship between Job Burnout and Turnover Intentions in the Context of Call Centers. Managing Service Quality: An International Journal, 22, 492-516. http://dx.doi.org/10.1108/09604521211281396

[9] Rod, M. and Ashill, N.J. (2013) The Impact of Call Centre Stressors on Inbound and Outbound Call Centre Agent Burnout. Managing Service Quality: An International Journal, 23, 245-264. http://dx.doi.org/10.1108/09604521311312255

[10] Pontes, M. and Kelly, C. (2000) The Identification of Inbound Call Center Agents' Competencies That Are Related to Callers’ Repurchase Intentions. Journal of Interactive Marketing, 14, 1441-1449. http://dx.doi.org/10.1002/1520-6653(200022)14:3<41::AID-DIR3>3.0.CO;2-M

[11] Holman, D. (2002) Employee Wellbeing at Call Centers. Human Resource Management Journal, 12, 35-50. http://dx.doi.org/10.1111/j.1748-8583.2002.tb00076.x

[12] Mukherjee, T. and Maheshwari, S. (2014) The Positive Side of Call Centers: An Indian Perspective. South Asian Journal of Global Business Research, 3, 36-53. http://dx.doi.org/10.1108/SAJGBR-03-2012-0030

[13] Kjellberg, A., Toomingas, A., Norman, K., Hagman, M., Herlin, R.-M. and Tornqvist, E.W. (2010) Stress, Energy and Psychosocial Conditions in Different Types of Call Centres. A Journal of Prevention, Assessment and Rehabilitation, 36, 9-25.

[14] Vigoda, E. (2000) Organizational Politics, Job Attitudes, and Work Outcomes: Exploration and Implications for the Public Sector. Journal of Vocational Behavior, 57, 326-347. http://dx.doi.org/10.1006/jvbe.1999.1742

[15] Khan, A.S., Anwar, F. and Ahmad, U.N.U. (2012) Comparative Analysis of Conventional versus Modern Appraisal Systems: An Empirical Evidence from Telecom Sector of Pakistan. Kuwait Chapter of Arabian Journal of Business and Management Review, 7, 101-124. 
M. A. S. Khan, J. G. Du

[16] Khan, A.S. and Anwar, F. (2012) An Exploratory Study of Appraisal Techniques from Pakistan Telecommunication Company Limited (PTCL). Arabian Journal of Business and Management Review (OMAN Chapter), 7, 51-70. http://dx.doi.org/10.12816/0002134 
Scientific Research Publishing (SCIRP) is one of the largest Open Access journal publishers. It is currently publishing more than 200 open access, online, peer-reviewed journals covering a wide range of academic disciplines. SCIRP serves the worldwide academic communities and contributes to the progress and application of science with its publication.

Other selected journals from SCIRP are listed as below. Submit your manuscript to us via either submit@scirp.org or Online Submission Portal.
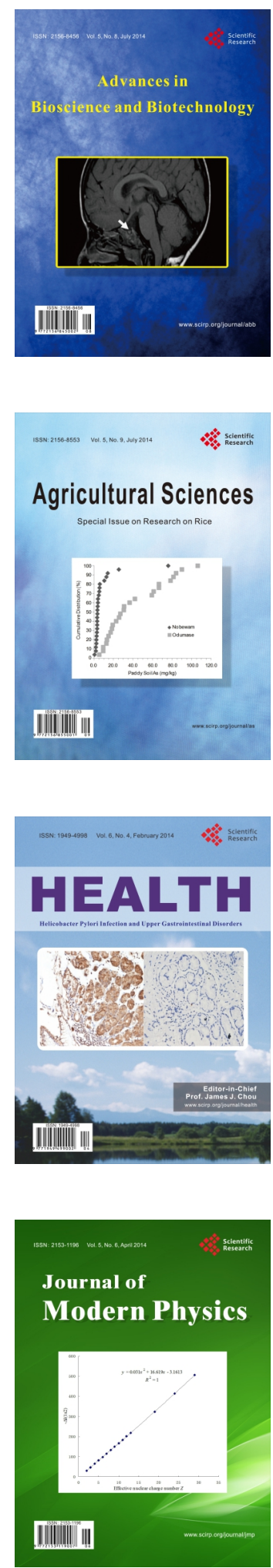
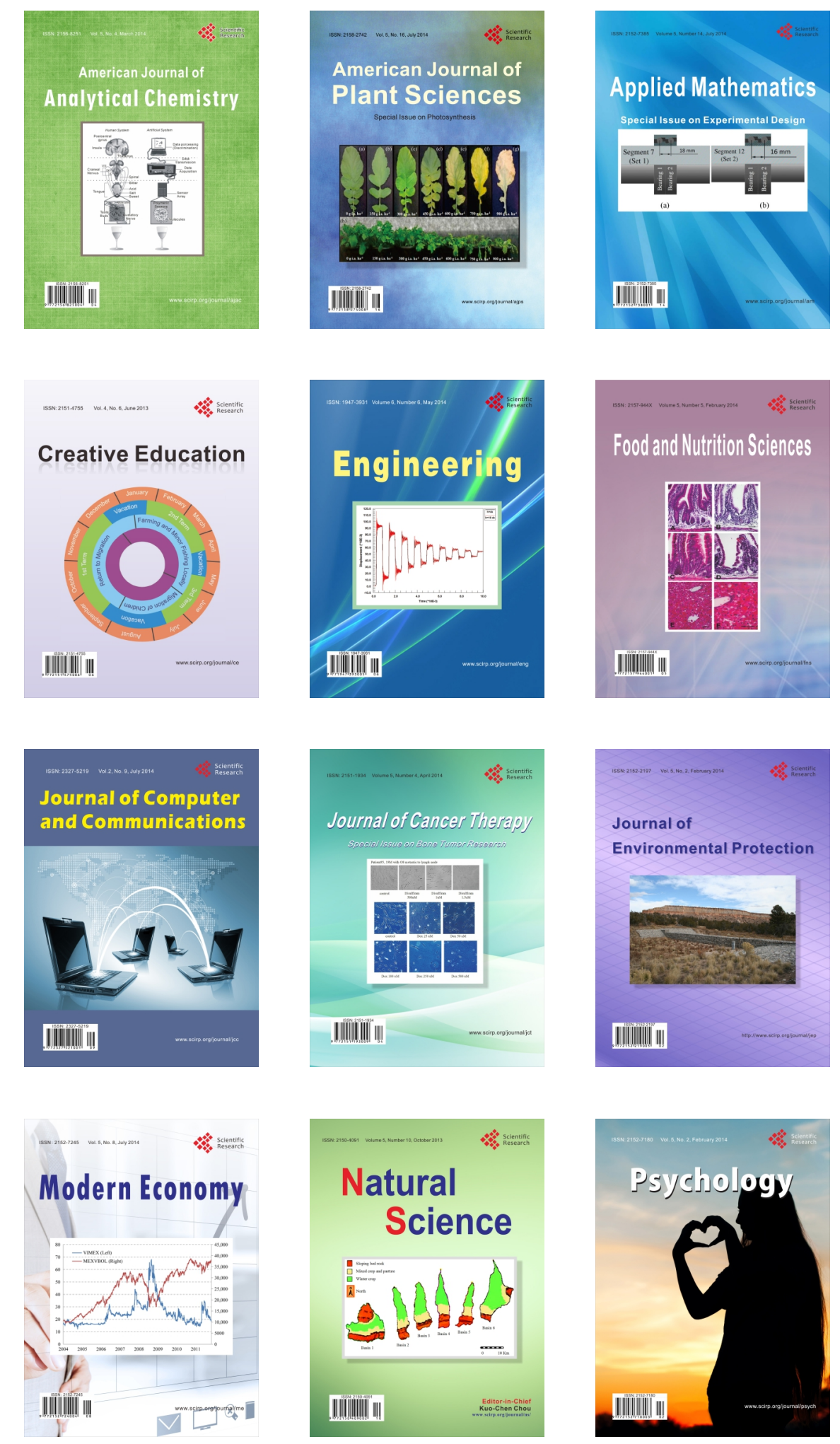